\title{
Clinical teachers and intern doctors' perception about the effectiveness of ongoing internship programme in undergraduate dental education in Bangladesh
}

\author{
Dr. Md. Immam Hossin ${ }^{1}$, Prof. Dr. Mohammad Faruque ${ }^{2}$, Prof. Md. Humayun Kabir Talukder ${ }^{3}$, Dr. Md. Rasel Ahmad ${ }^{4}$ \\ Brig Gen (Dr) Md Abdullah Al Harun, Brig Gen (Dr) Dipak Kumar Paul Chowdhury ${ }^{6}$
}

\begin{abstract}
Background: For the first 20 years or so after formal education in dentistry commenced at Glasgow in 1879, the manner of learning technical and clinical procedures was little different from what it had been since immemorial. In other words dental students learned by watching others until it was felt that they could be trusted to perform the procedure themselves.

Rationale: The intern year is the first level of hands-on training in dentistry and is an essential step in every dental surgeon's career. Opportunity to apply, consolidate and expand one's clinical knowledge, skills and also progressively increase one's responsibility for providing safe, high-quality patient care. Opportunity to develop overall patient management skill especially for the general dental practitioner. The intern year should provide a balance between education, training and clinical responsibility, enabling interns to develop the professional and personal competencies that result in good patient care and provide a foundation for lifelong learning.
\end{abstract}

Objectives: The present study was undertaken to identify the clinical teachers and intern doctors' perception about the effectiveness of ongoing internship programme in undergraduate dental education in Bangladesh.

Methods: This descriptive type of cross sectional study was conducted in six public and private dental colleges of Bangladesh. A semi-structured questionnaire based on 5-point Likert scale was used to collect the clinical teachers and intern doctors perceptions. The semi-structured questionnaire was prepared on the basis of logbook based internship training programme. Before administering the questionnaires to the respondents the investigator gave them an introductory idea about the purpose of the research.

Results: The study revealed that the majority of the clinical teachers $97.4 \%$ mentioned that the duration of internship training programme (one year) is not adequate and according to $94.9 \%$ teachers' opinion the duration of internship training programme should be 2 years. On the other hand $87.4 \%$ intern doctors mentioned that the duration of internship training programme (one year) is not adequate $94.6 \%$ intern doctors mentioned that the duration of internship training programme should be two. Majority $55 \%$ of the teachers mentioned that the training environment was almost supportive. Majority of the intern doctors mentioned that the environment was supportive to ensure adequate patients service.

Conclusion: To ensure excellence in all aspects of internship training programme, it can be concluded that intern doctors must need to acquire sufficient competencies in most of the clinical areas for their daily practice. There are many areas for further improvement through evaluating and developing the internship training programme as well as the logbook and strengthening the clinical environment in the institutes.

Key Words: Clinical teachers, Internship training, logbook, intern doctors perception, Competencies.

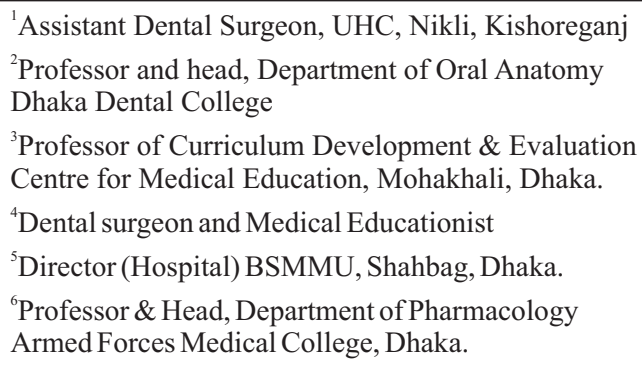

Address of correspondence: Dr. Md. Immam Hossin BDS (DDC), MMEd (BSMMU), FICD (USA)

Assistant Dental Surgeon and Medical Educationist

UHC, Nikli, Kishoreganj

Email: bulbulbds42@gmail.com

\section{Introduction}

Dental internship is a temporary position for the newly passed dental graduates with an emphasis on on-the job training rather than merely employment before they are qualified for actual job. The Interns' Training Programme is designed to improve and enhance the Interns' knowledge and skills in their practice of general dentistry, thereby facilitating reduced dependency upon specialists. It prepares the Interns to plan and deliver various dental treatment modalities with the required guidance from their mentors. Additionally, it prepares them to assess patients' general health status in relation to the anticipated dental treatment ${ }^{1}$. Providing basic life support is dentist's most important contribution until definitive treatment for a medical

Bangladesh Journal of Medical Education 2016;7(2):23-27. C 2016 Hossain et al., publisher and licensee Association for Medical Education. This is an Open Access article which permits unrestricted non-commercial use, provided the original work is properly cited. 
emergency can be given. It is important to assess the dental interns' knowledge, skills and competency regarding Dentistry-medical emergency interface ${ }^{2}$. Knowledge of medical emergencies by dental interns is important since they go for practice without supervision. This study was conducted to assess the awareness and knowledge of medical emergencies among dental interns in the southern part of India. Based on the results, dental curricula need to include more rigorous training in emergency management ${ }^{3}$. A significantly high level of satisfaction was found by the patients' responses, and they showed their trust and level of comfort toward the interns. Several questions were asked from the patients to evaluate their satisfaction towards treatment, doctor's behavior, and clinical environment. Although, we did not observe significant events among all the variables, we found a high level of patients' satisfaction toward the interns and clinics ${ }^{4}$. Measuring attitudes and awareness of practitioners toward infection control in prosthodontic clinic is very important to be conducted in the early years of practice. Enhancing and motivating dental students are essential for them to adopt attitudes and behaviors learned on infection control when they become professional dentists ${ }^{5}$. Isolation of teeth is an important factor for multiple procedures in dentistry. The value of isolation relates to reducing potential risk of cross infection between dental staff and patient. The rubber dam is the most widely used and considered to be the best method of infection control, in particular during root canal treatment ${ }^{6}$. The revolution of information technology and the great advances in computer capacity can effectively be utilized to enhance and improve dental practice and education. Computer usage in medical and dental education has grown as well to enhance traditional teaching strategies, and to provide new methods of learning ${ }^{7}$. Professional ethics in dentistry is one of the basic components for achieving success in dental practice because it ensures patients' confidence in adroitness of the practitioners as well as in the dental procedures to which they are subjected. The American Dental Association (ADA) defines dental ethics under five fundamental principles of the ADA Code that focuses patients' autonomy, nonmaleficence, beneficence, justice and veracity ${ }^{8}$. A "competency" is a complex behavior or ability essential for the general dentist to begin independent, unsupervised dental practice. Competence includes knowledge, experience, critical thinking and problem-solving skills, professionalism, ethical values, and technical and procedural skills. These components become an integrated whole during the delivery of patient care by the competent general dentist ${ }^{9}$. Assessment of interns' standard of care requires careful monitoring of their clinical performance and productivity. This is done as an integral part of dental education at King Saud University, College of Dentistry (KSU-CD), where the freshly graduate is required to undertake a twelve-month period as an intern before being fully registered as a licensed dentist ${ }^{10}$.

\section{Methodology}

This descriptive type of cross sectional study was conducted in six public and private dental colleges of Bangladesh after getting written permission from the principal of the respective dental colleges. Voluntary participation of the intern doctors was ensured and the names of the intern doctors as well as clinical teachers were kept confidential. The clinical teachers and intern doctors from the different dental colleges were the study population; among them two hundred (200) intern doctors and forty clinical teachers (40) were taken as sample by convenient sampling. Data collection instrument was a semi-structured questionnaire with 5-point Likert scale with maximum score 5 and minimum score 1. The instruments were pretested in Rajshahi medical college dental unit. The researcher himself visited selected dental colleges. He was introduced himself to the principal of the dental colleges and the teachers of all the clinical departments to conduct the study. Specific time was taken from the clinical teachers and to brief the intern doctors about the purpose and benefit of the study. The intern doctors were briefed about the questionnaire. The investigator himself collected all the data with prior permission of the principles and heads of the concerned departments. The semi-structured questionnaire was prepared on the basis of logbook based internship training programme. Before administering the questionnaires to the respondents the investigator gave them an introductory idea about the purpose of the research. All the collected data were checked manually. Data entry, editing, processing and analysis have been done by using 19 version of SPSS compute software programme. Interpretations were done subsequently. Data were presented by tables and graphs with necessary description where necessary for easy understanding and interpretation. Name of the colleges, teachers, students were not being disclosed. Findings of the study were used only for research purpose.

\section{Results}

Table 1 shows out of 36 teachers 6(16.67) mentioned that duration of training for the interns in prosthodontics should be 12 weeks, 10(27.78) mentioned that duration of training for the interns in oral and maxillofacial surgery should be 13 weeks, 5(13.89) mentioned that duration of training for the interns in periodontology should be 10 weeks and 12(33.33) mentioned that duration of training for the interns in Conservative Dentistry should be 14 weeks.

Table 1: Distribution of the teachers by their opinion regarding the duration of training for the intern doctors in individual subject

\begin{tabular}{|l|c|c|c|}
\hline $\begin{array}{l}\text { Duration of training } \\
\text { for the intern doctors } \\
\text { in individual subject }\end{array}$ & Frequency & Percent (\%) & Mean \\
\hline Prosthodontics & 6 & 16.67 & 12 Weeks \\
\hline Children dentistry & 2 & 5.56 & 11 Weeks \\
\hline $\begin{array}{l}\text { Oral \& Maxillofacial } \\
\text { Surgery }\end{array}$ & 10 & 27.78 & 13 Weeks \\
\hline Periodontology & 5 & 13.89 & 10 Weeks \\
\hline Orthodontics & 1 & 2.78 & 12 Weeks \\
\hline Conservative dentistry & 12 & 33.33 & 14 Weeks \\
\hline Total & 36 & 100.0 & \\
\hline
\end{tabular}

Bangladesh Journal of Medical Education 2016;7(2):23-27. 
aTable 2 shows different level of core competencies, out of 200 intern doctors majority 164(82) mentioned satisfied, $36(18)$ were very satisfied in scope of proper history taking and recording. 190(95) mentioned very satisfied in scope of proposing investigation to the patients. 181(90.5) mentioned that they were satisfied in scope of making diagnosis. 111(55.5) mentioned satisfied and 59(29.5) were dissatisfied in dealing with dental emergencies e.g. (faint, syncope, acute hypoglycemia etc. 162(81) mentioned that they were satisfied and 22(11) mentioned dissatisfied in scope of performing local anaesthesia. 130(66) mentioned satisfied,19(9.6) were neither satisfied nor dissatisfied, 45(22.8) were dissatisfied in satisfaction about the competencies acquiring.

Table 2: Distribution of the intern doctors by their opinion about the statements in relation to competencies $(\mathrm{n}=200)$

\begin{tabular}{|c|c|c|c|c|c|c|}
\hline \multirow[t]{2}{*}{ Statements in relation to the competencies } & \multicolumn{5}{|c|}{ Frequency $(\%)$} & \multirow[t]{2}{*}{ Total } \\
\hline & VD & D & NSND & $\mathbf{S}$ & VS & \\
\hline Scope of proper history taking and recording & - & - & - & $164(82)$ & $36(18)$ & 200 \\
\hline Scope of proposing investigations to the patients & - & - & $1(.5)$ & 190(95) & $9(4.5)$ & 200 \\
\hline Scope of counselling the patient and or attendants & - & $2(1.0)$ & $10(5)$ & $183(91.5)$ & $5(2.5)$ & 200 \\
\hline Scope of making diagnosis & - & $4(2)$ & $10(5)$ & $181(90.5)$ & $5(2.5)$ & 200 \\
\hline Scope of writing prescriptions & - & $3(1.5)$ & $4(2)$ & $182(91.5)$ & $10(5)$ & 200 \\
\hline $\begin{array}{l}\text { Dealing with dental emergencies e.g. (faint, syncope, acute } \\
\text { hypoglycemia etc.) }\end{array}$ & $10(5)$ & $59(29.5)$ & $14(7)$ & $111(55.5)$ & $6(3)$ & 200 \\
\hline $\begin{array}{l}\text { Scope of interpretation of investigations and records (e.g. X-ray, } \\
\text { OPG finding etc.) }\end{array}$ & $2(1)$ & $94(47)$ & $21(10.5)$ & $81(40.5)$ & $2(1)$ & 200 \\
\hline Scope of performing local anaesthesia & - & $22(11)$ & $10(5)$ & $162(81)$ & $6(3)$ & 200 \\
\hline Scope of intraoral examination & $1(.5)$ & $6(3)$ & $12(6)$ & $178(89)$ & $3(1.5)$ & 200 \\
\hline Scope of relevant discussion with the supervisors & $2(1)$ & $36(18.1)$ & $29(14.6)$ & $131(65.8)$ & $1(.5)$ & 199 \\
\hline Satisfaction about the competencies acquiring & $2(1)$ & $45(22.8)$ & $19(9.6)$ & $130(66)$ & $1(.5)$ & 197 \\
\hline
\end{tabular}

( $\mathbf{V D}=$ Very dissatisfied, $\mathbf{D}=$ Dissatisfied, $\mathbf{N S N D}=$ neither satisfied nor dissatisfied, $\mathbf{S}=$ Satisfied, $\mathbf{V S}=$ Very satisfied)

Table 3: Distribution of the intern doctors by their opinion regarding the environment to ensure adequate patient service and as well as optimum training of the intern doctors

\begin{tabular}{|c|c|c|c|c|c|c|}
\hline \multirow{2}{*}{$\begin{array}{l}\text { Environment to ensure adequate patient service and as } \\
\text { well as optimum training of the intern doctors }\end{array}$} & \multicolumn{5}{|c|}{ Frequency (\%) } & \multirow[t]{2}{*}{ Total } \\
\hline & VD & D & NSND & $\mathbf{S}$ & VS & \\
\hline $\begin{array}{l}\text { Adequacy of the training facility (e.g. dental units, minor OT, } \\
\text { outdoor, diagnostic room etc.) }\end{array}$ & $9(4.5)$ & $116(58)$ & $3(1.5)$ & $59(29.5)$ & $13(6.5)$ & 200 \\
\hline $\begin{array}{l}\text { Sterilization facility (all surgical and non-surgical dental } \\
\text { instruments etc.) }\end{array}$ & $18(9)$ & $99(49.5)$ & $1(.5)$ & $78(39)$ & $4(2)$ & 200 \\
\hline $\begin{array}{l}\text { Availability of training aids (e.g. all necessary dental } \\
\text { instruments, restorative materials, and laboratory materials } \\
\text { etc.) }\end{array}$ & $24(12)$ & $114(57)$ & $10(5)$ & $49(24.5)$ & $3(1.5)$ & 200 \\
\hline Availability of laboratory facilities & $15(7.5)$ & $81(40.5)$ & $21(10.5)$ & $81(40.5)$ & $2(1)$ & 200 \\
\hline $\begin{array}{l}\text { Availability of diagnostic facility (e.g. CBC, HBsAg, BT, CT } \\
\text { etc.) }\end{array}$ & $68(34)$ & $120(60)$ & $10(5)$ & $1(.5)$ & $1(.5)$ & 200 \\
\hline $\begin{array}{l}\text { Safe practices in relation to patients; doctors; and other health } \\
\text { care provider (help to prevent cross infection, laboratory } \\
\text { hazards, protection from radiation etc.) }\end{array}$ & $1(.5)$ & $85(42.5)$ & $10(5)$ & $101(50.5)$ & $3(1.5)$ & 200 \\
\hline Availability of reference books & - & $61(30.5)$ & $15(7.5)$ & $121(60.5)$ & $3(1.5)$ & 200 \\
\hline Availability of internet facility & $21(10.5)$ & $91(45.5)$ & $16(8)$ & $71(35.5)$ & $1(.5)$ & 200 \\
\hline $\begin{array}{l}\text { Availability of supporting staffs (dental assistants, laboratory } \\
\text { technicians etc.) }\end{array}$ & - & $134(67)$ & $31(15.5)$ & $34(17)$ & $1(.5)$ & 200 \\
\hline Intern doctor patient ratio & - & $7(3.5)$ & $17(8.5)$ & $174(87)$ & $2(1)$ & 200 \\
\hline Intern doctor trainers ratio & - & $31(15.6)$ & $9(4.5)$ & $158(79.4)$ & $1(.5)$ & 199 \\
\hline
\end{tabular}

(VD=Very dissatisfied, $\mathbf{D}=$ Dissatisfied, $\mathbf{N S N D}=$ neither satisfied nor dissatisfied, $\mathbf{S}=$ Satisfied, VS=Very satisfied)

Bangladesh Journal of Medical Education 2016;7(2):23-27. 
Table 3 shows out of 200 intern doctors majority 116(58) mentioned dissatisfied in adequacy of the training facility (e.g. dental units, minor OT, outdoor, diagnostic room etc.) Majority 99(49.5) mentioned dissatisfied, 78(39) were satisfied in sterilization facility (all surgical and nonsurgical dental instruments etc.) Majority 114(57) mentioned dissatisfied in availability of training aids (e.g. all necessary dental instruments, restorative materials, and laboratory materials etc.) Majority 120(60) mentioned dissatisfied and 68(34) were very dissatisfied in availability of diagnostic facility (e.g. CBC, HBsAg, BT, CT etc.) Majority 101(50.5) mentioned satisfied in safe practices in relation to patients; doctors; and other health care provider (help to prevent cross infection, laboratory hazards, protection from radiation etc. Majority 134(67) mentioned dissatisfied in availability of supporting staffs (dental assistants, laboratory technicians etc.) Majority 174(87) mentioned satisfied in intern doctor patient ratio.

\section{Discussion}

Table 1 shows out of 36 teachers 6 (16.67) mentioned that duration of training for the interns in prosthodontics should be 12 weeks, 10(27.78) mentioned that duration of training for the interns in oral and maxillofacial surgery should be 13 weeks, 5(13.89) mentioned that duration of training for the interns in periodontology should be 10 weeks and 12(33.33) mentioned that duration of training for the interns in Conservative Dentistry should be 14 weeks. A study conducted by Lalloo et al.(2009) ${ }^{1}$ showed that out of 445 students responded there were slightly more female respondents $(56.2 \%)$, more than two-thirds $(70.8 \%)$ were younger than 24 years of age, and half $(51.0 \%)$ were from years 1 and 2 of their degree program. Less than half $(40.2 \%)$ of the respondents were supportive of an internship period. More females (43.6\%) were supportive of the scheme compared to males (25.5\%). Almost a half (46.7\%) of students younger than 22 years of age were supportive compared to a third (33.6\%) of students older than 24 years. Almost all students equally preferred a 6-month or 1-year internship period. Table 2 shows different level of core competencies, out of 200 intern doctors majority 164(82) mentioned satisfied, 36(18) were very satisfied in scope of proper history taking and recording.190 (95) mentioned very satisfied in scope of proposing investigation to the patients. 181(90.5) mentioned that they were satisfied in scope of making diagnosis. 111(55.5) mentioned satisfied and 59(29.5) were dissatisfied in dealing with dental emergencies e.g. (faint, syncope, acute hypoglycemia etc. 162(81) mentioned that they were satisfied and 22(11) mentioned dissatisfied in scope of performing local anaesthesia. 130(66) mentioned satisfied, 19(9.6) were neither satisfied nor dissatisfied, 45(22.8) were dissatisfied in satisfaction about the competencies acquiring. A study conducted by Anjum et al.(2014) showed that 227 interns participated, of which $25.1 \%$ were males and $74.9 \%$ females. $52.4 \%$ followed the six steps involved in rational prescription process, whenever they prescribed medicines. A study conducted by Fazel, et al $(2008)^{13}$ in which that out of 300 questionnaires distributed in the 30 provinces of the country, 250 questionnaires $(83 \%)$ were returned. While most of the participants considered the competencies as necessary for an Iranian dentist, less than $40 \%$ of the respondents believed that the graduates acquire the most required competencies of the profession during the current educational program. A study conducted by Licari et. al. $(2008)^{14}$ in which Fewer than half (46 percent) of the respondents were able to identify the conventional definition of competency that was stated as "a set of skills, knowledge, and values that characterize beginning dentists." Almost a quarter each identified "competency" as a type of clinical examination format (26 percent) or roughly the same as a clinical discipline ( 25 percent). Nine percent associated the primary meaning of "competency" as an accreditation requirement. A study conducted by Gerrow et. al. $(2006)^{15}$.The survey asked participants to supply demographic information and rate each of the forty-six competencies on a 5-point Likert scale. The response rate was 43.1 percent ( 315 total usable responses). Self-reported demographic data was used to create respondent subgroups. The participants rated all of the competencies quite high with thirty-six of the forty-six receiving rankings averaging 4.0 or higher on the 5-point scale. No competency received a ranking averaging lower than 3.0. A study conducted by Willis et. al. (2009) ${ }^{16}$. The ADEA Competencies for the New General Dentist contain a significant number of practice management-related competencies. To date, these have been taught primarily in a lecture format in the third and fourth years of the dental curriculum. Presenting information in this way only satisfies the lower level learning skills, not the skills needed to become a competent general dentist.

\section{Conclusion}

In the present study, the intern doctors reported that they have acquired greater clinical experiences in few areas during their internship training in the hospital. The majority of the interns were not satisfied on their acquired competencies in most of the areas during their training programme. According to their opinion, lack of supervision and feedback in the clinical settings, inadequacy of assessment of the interns in all level are the key factors so that the intern doctors were not satisfied with the overall internship training programme. Lastly it can be concluded that intern doctors must need to acquire sufficient competencies in most of the clinical areas for their daily practice. There are many areas for further improvement through evaluating and developing the internship training programme as well as the logbook and strengthening the clinical environment in the institutes.

\section{References}

1. Lalloo R, Johnson NW, Blinkhorn A, Ichhim P,(2009), Austrslian dental students views on a compulsary internship schenme, Medical journal of Australia, Vol.185,no.1,pp.59-65.

Bangladesh Journal of Medical Education 2016;7(2):23-27. 
2. Jodalli PS. Arkola AV, (2012), Evaluation of knowledge, experience and perceptions about medical emergencies amongst dental graduates (Interns) of Belgaum City, India. J Clin Exp Dent. vol.4, no.1, PP. 14-18.

3. Elanchezhiyan S, Elavarasu S, Venrila K, Renukadeui R, Mahabob MN, Scntil Kumar B, Raja S,(2012), Awareness of dental and Medical Emergencies among dental interns in southern India : An Analytical study, Journal of Dental Education, vol.77, no.3,pp.364-368.

4. Aws S, ArRejaie, Nawasrah AM, Khan SQ, Farooqi FA, Somali R, Al-mudani WF, (2014), patients perception toward various dental treatments provided in the internship program, Saudi Med J, vol.35,no.12,pp.1513-1516.

5. Alshiddi IF, (2015), Attitude and awareness of dental students and interns toward infection control measures in prosthodontic clinics, Eur J Dent,vol.7,no.2,pp.1519.

6. Al-Abdulwahhab BM,Al-Thabit H, Al-Harthi A, AlAshagi A, Al-Qabbani F, Al-Ghamdi S, Al-Taher R, (2012), The attitudes of dental interns to the use of the rubber dam at Riyadh Dental College, Saudi Endod J, vol.2, no.1 pp.75-79.

7. Barrak AA, Yami RA, Bamajboor A, (2013), Assessment of skills and Attitude of Dental Students and interns toward e-learning in KSU. International Journal of Excellence in Education, Vol. 5, No. 01, PP. 101-111.

8. Al-Zahin SA,Al-Sadhan SAR, Ahmedani MS, (2014), Penception of BDS Students and fresh graduates about significence of profensional etics in dentistry, J Pak Med Assoc, Vol. 64, no. 2, PP. 118-123.
9. ADEA Competencies for the New General Dentist, (2011); Journal of Dent Education; Vol. 75, No.7, pp.932-935.

10. Sadig W,(2004), An assessment of clinical productivity of dental interns at king saud university, Pakistan Oral and Dental Journal, vol.27, no.1, pp.107-112.

11. Anjum M, Parthasanathi P, Monica M, Yadav K, Irram A, Keerthi T, Kistigari P, (2014), Evaluating the knowledge of interns in preseribing basic drugs used in dentistry - Across sectional study, wedmed central> orginal Articles , pp.3-11.

12. Internship logbook by BM\&DC (2007)

13. Fazel A, Jafari A, Khami MR, et al. 2001, 'Dental Curriculum Revision in Iran: Dentists' Perspective on Achievement of Essential Competencies through National Curriculum', Beheshti Univ Dent J. Vol.18, No.4,pp.140.

14. Frank W. Licari, D.D.S.; David W. Chambers, Ed.M., M.B.A., Ph.D. "Some Paradoxes in Competency-Based Dental Education" Journal of Dental Education, Vol.72, Num.1, pp-1-18.

15. Jack D. Gerrow, D.D.S., M.S., M.Ed.; H. Joseph Murphy, Ed.D.; Marcia A. Boyd, D.D.S., M.A., L.H.D. (Hon). "Competencies for the Beginning Dental Practitioner in Canada: A Validity Survey" Journal of Dental Education.Vol.70, Num.10, pp.1076-1080.

16. David O. Willis, D.M.D., M.B.A., C.F.P. "Using Competencies to Improve Dental Practice Management Education". Journal of Dental Education. Vol.73, Num.10, pp-1144-1152.

Bangladesh Journal of Medical Education 2016;7(2):23-27. 